\title{
CAPÍTULO XIX
}

\section{CARACTERIZACIÓN DEL SECTOR MICROEMPRESARIAL DEL ESPINAL TOLIMA, AÑO 2020}

\section{Robert Alexander Guzmán}

Magíster en Educación, Contador Público, Investigador Junior en Colciencias. Perteneciente al grupo de investigación SICOFAS de la Institución de Educación Superior ITFIP. Orcid: https://orcid.org/0000-0003-2608-8744. Correo electrónico: roguzman@itfip.edu.co.

\section{Elizabeth Palma Cardoso}

Doctorante en Administración Gerencial, Magíster en Educación, Especialista en Docencia Universitaria, Contador Público. Líder del grupo de investigación SICOFAS (ITFIP), Coordinadora de investigación de Contaduría Pública, editora de REVISTA INNOVA ITFIP y libros de investigación, Orcid: https:// orcid.org/0000-0002-9650-8305. Correo electrónico: epalma@itfip.edu.co.

\section{Mario Fernando Díaz Pava}

Magíster en Planeación Territorial y Gestión ambiental, Especialista en Derecho Administrativo y Constitucional, Especialización en Telecomunicaciones, Profesional en Derecho, Rector del Instituto Tolimense de Formación Técnica Profesional ITFIP. Integrante del grupo de investigación SICOFAS. https:// orcid.org/0000-0003- 0842-0651. Correo electrónico: mdiaz@itfip.edu.co.

\section{Orlando Varón Giraldo}

Magíster en Educación, Especialista en Docencia Universitaria, Administrador Financiero, Docente de planta del ITFIP, investigador Junior en Colciencias. Coordinador del programa Contaduría Pública del ITFIP Integrante Grupo de Investigación SICOFAS. Orcid: https://orcid.org/0000-0002-0184-7284. Correo electrónico: ovaron@itfip.edu.co.

\section{Ruth Erika Morales Lugo}

Magiíter en Sistemas Integrados de Gestión, Especialista en Ingeniería de la Calidad y el Comportamiento, Ingeniera Industrial, Decana de la Facultad de Economía, Administración y Contaduría del ITFIP, Investigadora del grupo SICOFAS de Contaduría Pública del ITFIP. ORCID: https://orcid.org/00000002-0754-3249. Correo electrónico: rmorales@itfip.edu.co. 


\title{
Resumen
}

En Colombia el tejido empresarial representado por las empresas responsables de la dinámica económica, cumplen su labor de generar su aporte desde cada uno de su objeto económico, sin embargo, es relevante la participación e importancia que tienen las microempresas en cada una de las regiones del país. El presente capítulo describe las características del sector micro en el Espinal Tolima, a partir de la base de datos reportada por la Cámara de Comercio del Sur y Oriente del Tolima a junio de 2020, la cual se abordó desde un enfoque cualitativo realizándose un análisis descriptivo para identificar las diferentes variables proporcionadas en la base de datos como, la clasificación industrial internacional uniforme (CIIU) de las actividades económicas, tiempo de matrícula mercantil, fecha de renovación, tipo de organización, ubicación. Como principales resultados se encuentran que al cierre de Junio de 2020, se habían renovado la matrícula mercantil en un $43 \%$ de las micro registradas en cámara de comercio, y el 57\% se registran con última fecha de renovación en el 2019. El 40\% de las micro se encuentran ubicadas en el sector centro y un $76 \%$ desarrollan actividades de comercio al por menor, de igual forma el análisis de la base de datos determinó que de las microempresas inscritas a la fecha de estudio el 33\% lleva más de 10 años ejerciendo su actividad comercial desde su registro mercantil. Se llegó a la conclusión que este tipo de empresas tienen la ventaja de adaptarse de una manera más rápida a los cambios que le presente el entorno.

Palabras clave: business activity, business classification, micro-business.

\section{CHARACTERIZATION OF THE MICROENTERPRISE SECTOR OF THE TOLIMA SPINAL, YEAR 2020}

\begin{abstract}
In Colombia, the business fabric represented by the companies responsible for the economic dynamics, fulfill their task of generating their contribution from each of their economic object, however, the participation and importance of micro-enterprises in each of the regions of the country is relevant. country. This chapter describes the characteristics of the micro sector in Espinal Tolima, based on the database reported by the Chamber of Commerce of the South and East of Tolima as of June 2020, of which a descriptive analysis was carried out identifying the different variables provided in the database such as the uniform international industrial classification (ISIC) of economic activities, time of commercial registration, date of renewal, type of organization, location. The main results are that at the end of June 2020, which was approached from a qualitative approach, performing a descriptive analysis to the commercial registration had been renewed in $43 \%$ of the micro registered in the chamber of commerce, and $57 \%$ were registered with the last renewal date in $2019.40 \%$ of the micro companies are located in the central sector and $76 \%$ carry out retail trade activities, in the same way the analysis of the database determined that of the micro companies registered at
\end{abstract}


the date of study, $33 \%$ had more than 10 years exercising its commercial activity from its commercial register. Reaching the conclusion that these types of companies have the advantage of adapting more quickly to changes in the environment

Keywords: Classification of companies, Business activity, Micro-enterprise.

\section{Proyecto: Análisis de Microempresas del Espinal Tolima. Financiado por ITFIP}

\section{Introducción}

Las microempresas constituyen una modalidad productiva que aportan al consumo de bienes y servicios, y a su vez son generadores de estos, en menor medida pero que en conjunto son consideradas una fuente importante de crecimiento al producto interno bruto de cualquier economía. Para Guerrero (2001) en las regiones las microempresas son de una gran relevancia y por tanto no deben ser desamparadas por las autoridades gubernamentales, ellas están presente hasta en las pequeñas economías por ejemplo de los barrios, donde se constituyen en alma o eje motor de la socioeconomía del área. Por lo anterior, se deben considerar no menos importantes y es importante conocer sus características e importancia dentro de cualquier situación economica. Este artículo, abordó una caracterización de variables de análisis presentes en la base de datos suministrada por la cámara de comercio del sur y oriente del Espinal, con el objetivo de conocer acerca de este grupo de empresas. Inicialmente, se describe la importancia que tiene la actividad microempresaria a partir de la revisión de la literatura, posteriormente se presenta la normatividad que se rige en Colombia para la clasificación de las empresas a fin de determinar su tamaño, modificada en el 2019 por el decreto 957 de 2019 y finalmente como resultado del análisis y descripción de la base de datos para la micro en el municipio del espinal Tolima se presentan las características importantes que se identifican este tipo de empresas.

Identificar las características de este tipo de organización empresarial permitirá establecer estrategias y mejorar en sus procesos que no apuntan solo a la generación de utilidades, como señalan Bautista et al., (2020) las organizaciones eran vistas generadoras de utilidades y bastantes ingresos para los dueños de las mismas, actualmente tal premisa va más allá de esta inferencia, ya que se ha buscado la manera de incorporar y adoptar estrategias, así como procesos de innovación y responsabilidad social, acogiéndose como una parte, forma y estructura integral en la estrategia del negocio. 


\section{Fundamentación teórica}

\section{La Actividad Microempresarial}

Para Díaz (2010) las microempresas se constituyen como uno de los soportes del desarrollo en especial el endógeno, esto porque se convierte en una fuente de empleo para los pobladores de la zona. Por tanto, el conjunto de microempresas que puede tener un país es fuente de progreso, teniendo en cuenta que éstas en su conjunto impulsan la economía al consumir materias primas elaboradas como insumos para sus productos, igualmente se reconoce su poder de demanda de bienes. La microempresa es un pilar muy influyente en la creación de empleo, así como en la contribución al PIB nacional. Estas micro-organizaciones son una forma de disminuir los niveles de indigencia y pobreza, ya que pueden impulsar acciones o actividades económicas. "Sin embargo, es la empresa menos apoyada tanto por las instituciones gubernamentales como privadas" (Díaz, 2010, p. 275).

Por ello, es urgente gestionar el apoyo tanto al gobierno nacional como municipal para que se den beneficios a esta clase de negocios y así, continúen con la sostenibilidad y el aporte laboral a la sociedad, como siempre lo han venido haciendo. Por consiguiente, es de aclarar "que las actividades económicas más recurrentes en el municipio El Espinal, son las famiempresas o micro empresas". (Palma et al., 2019, p.13)

Es conveniente expresar la manera como se refieren a las microempresas los autores García et al., (citado por Benito, 2007) “y se pueden resumir en:

- $\quad$ Promueve las actividades económicas de la localidad.

- $\quad$ Son capaces de adaptarse al ambiente donde se desenvuelve y adicionalmente los cambios tecnológicos que son tan comunes e importantes en la actualidad.

- La inversión de capitales es baja y pueden usarse los ahorros personales o familiares.

- Tanto los inversores como los trabajadores se conocen. 
- No requiere de grandes dimensiones estructurales o empresariales.

- $\quad$ La propiedad puede ser individual, pero también asociativa.

Así mismo, se hace necesario señalar la importancia que tiene la gestión empresarial y competitividad, los cuales son considerados por Batista y Guacari (2018) como los "fundamentos que soportan la administración de cualquier empresa o negocio e incluso se podría decir que son complementarios para garantizar la supervivencia de una organización en este entorno permeado por el cambio permanente que genera nuevos retos" (p. 77). Lo anterior, tiene relación con adoptar nuevas tácticas para sacar adelante las empresas mediante adecuadas estrategias de competitividad, innovación y gestión empresarial, (Barragán y Quintero 2019; Reyes et al., 2019).

Todo esto, sin dejar atrás "el desarrollo tecnológico por medio de la utilización de herramientas de Información y Comunicación (TIC); con el fin de poder tener elementos de juicio para dar soluciones a las diferentes problemáticas dentro del contexto" (Barragán y Zarete, 2017, p.36). Lo que permite afirmar a Ceballos et al. (2019) que "un número significativo de entidades del sector público y privado han implementado en los últimos años esta metodología para optimizar operaciones administrativas y facilitar el acceso a las transacciones que componen su quehacer productivo y operacional" (p. 64).

Las microempresas pueden operar en diferentes mercados, Martínez (1989, p.25) ha señalado que este tipo de empresas ha desarrollado características operativas como la adaptabilidad, capacidad en la generación de recursos, exposición a riesgos crecientes en correspondencia a su dinamismo económico, administración de tensiones que se generan en el desarrollo de la gestión de la microempresa como intento permanente de su adaptabilidad y la superación de riesgos. Así mismo, se caracteriza porque la gran mayoría de las empresas en Colombia, son microempresas pertenecientes al grupo 3 conforme al marco normativo contable, las cuales tienen ciertas características que deben cumplir, además, es importante decir que los comerciantes al por menor se encuentran en este grupo, debido a que son negocios pequeños que no superan más de diez empleados y llevan una contabilidad simplificada. (Varón et al., 2018, p.28), de igual manera es importante como lo indican Moreno y Valencia (2019), ya que 
las empresas han encontrado formas eficientes de realizar sus procesos utilizando los avances tecnológicos que día a día se van desarrollando y poniendo a disposición de las organizaciones, teniendo en cuenta esta facilidad de adaptabilidad las microempresas no deben dejar de lado la incorporación de la tecnología en el desarrollo económico (p. 13).

Por su aporte, es innegable la representación de esta clase de negocios en la economía del país, en 2016 un estudio de Confecamaras presidida por Julián Domínguez (2016) arrojó que en el país $94,7 \%$ de las empresas registradas son microempresas y 4,9\% pequeñas y medianas, por lo que se deben considerar a este tipo de empresas como una de las más importantes impulsores de la economía en Colombia, como generadores de empleo, de consumo y ofrecimiento de todo tipo de bienes y servicios. Un indicador fundamental para entender la dinámica empresarial de la región, es el número de matrículas nuevas y renovaciones en la Cámara de Comercio. (Díaz, et. al., 2018 p. 45).

En abril de 2020, la Red de Cámaras de Comercio Confecamaras, en su estudio Nacional de Medición de Impacto del COVID-19 para el sector empresarial, se reafirma que en el tejido empresarial de Colombia las microempresas tienen una mayor representación, en el estudio en el cual participaron 20.035 empresas de 691 municipios, el 92.2\% de ellas se clasificaban dentro del tamaño de microempresas, tal cual se observa en la figura 1. (Confecamaras, 2020).

\section{Figura 1}

Clasificación Tamaño de Empresas. Confecamaras 2020

\section{Las empresas encuestadas a la fecha mantienen la distribución del stock total de empresas en el país, $92 \%$ de ellas son microempresas}

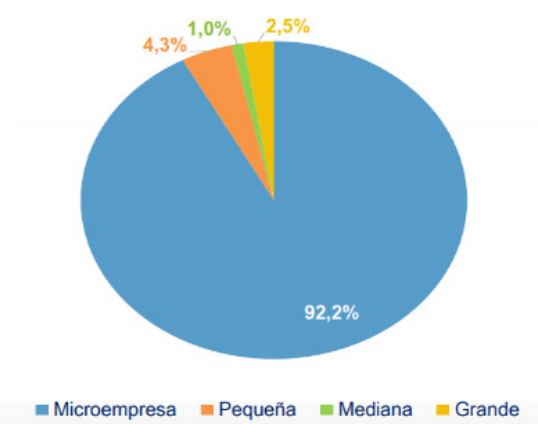

Fuente: Confecamaras (2020). 


\section{Clasificación de las Empresas en Colombia}

En Colombia el decreto 957 del 5 de junio de 2019, estableció una nueva clasificación del tamaño empresarial basada en el criterio único de ingresos por actividades ordinarias, establecidos en unidad de valor tributario (UVT), mediada mucho más real, ya que toma en cuenta las diferencias del sector, definiendo categorías que permiten identificar el tamaño de las empresas en los tres grandes sectores de cualquier economía, a saber, el de servicios y comercio, el de la manufactura y el económico.

En ese sentido, Restrepo (2019) señala que la nueva clasificación es fundamental para mejorar la información sobre el tejido empresarial colombiano ya que adopta un criterio más claro y eficiente, que aporta mejores insumos para la toma de decisiones de política pública y, así mismo, ayuda a focalizar los programas en beneficio de las MIPYME's.

Ahora bien, cuando se hace referencia al ingreso de actividades ordinarias se toman en cuenta las ventas brutas cuyo origen son las acciones habituales de la organización, no se incluyen las inversiones o financiamiento, esto dependiendo del marco de información financiera que suela manejar la organización. El decreto 957, adicionalmente establece, que esos ingresos serán designados con base en los ingresos generados al año inmediatamente anterior haciendo el corte al 31 de diciembre y para la certificación del tamaño empresarial, será necesario que la organización expida un certificado donde haga constar sus ingresos para el año en cuestión.

Por su parte, las personas naturales podrán expedir la certificación ellas mismas, mientras que la certificación de las personas jurídicas estará a cargo de su representante legal, su contador o el revisor fiscal de estar obligado a tener uno. (Palma et al., 2019).

Los paramentos de clasificación quedaron establecidos en la tabla 1 de la siguiente forma: 


\section{Tabla 1}

Rangos para la Definición del Tamaño Empresarial. "Decreto 957 de 2019”

\begin{tabular}{|c|c|c|c|}
\hline & Microempresa & Pequeña empresa & Mediana empresa \\
\hline $\begin{array}{l}\text { Sector } \\
\text { manufacturero }\end{array}$ & $\begin{array}{l}\text { Ingresos iguales o } \\
\text { inferiores a } 23.563 \\
\text { UVT ( } \$ 807.504 .000 \\
\text { por el año 2019). }\end{array}$ & $\begin{array}{l}\text { Ingresos superiores a } \\
23.563 \text { UVT, e iguales } \\
\text { o inferiores a } 204.995 \\
\text { UVT (\$7.025.179.000 } \\
\text { por el año 2019). }\end{array}$ & $\begin{array}{l}\text { Ingresos superiores a } \\
204.995 \text { UVT, e iguales } \\
\text { o inferiores a } 1.736 .565 \\
\text { UVT (\$59.512.083.000 } \\
\text { por el año 2019). }\end{array}$ \\
\hline $\begin{array}{l}\text { Sector de } \\
\text { servicios }\end{array}$ & $\begin{array}{l}\text { Ingresos inferiores o } \\
\text { iguales a } 32.988 \text { UVT } \\
\text { ( } \$ 1.130 .498 .000 \text { por el } \\
\text { año 2019). }\end{array}$ & $\begin{array}{l}\text { Ingresos superiores } \\
\text { a } 32.988 \text { UVT, e } \\
\text { inferiores o iguales } \\
\text { a } 131.951 \text { UVT } \\
(\$ 4.521 .961 .000 \text { por } \\
\text { el año 2019). }\end{array}$ & $\begin{array}{l}\text { Ingresos superiores } \\
\text { a } 131.951 \text { UVT, e } \\
\text { inferiores o iguales } \\
\text { a } 483.034 \text { UVT } \\
\text { ( } \$ 16.553 .575 .000 \text { por el } \\
\text { año 2019). }\end{array}$ \\
\hline Sector comercio & $\begin{array}{l}\text { Ingresos inferiores o } \\
\text { iguales a } 44.769 \text { UVT } \\
\text { ( } \$ 1.534 .233 .00 \text { por el } \\
\text { año 2019). }\end{array}$ & $\begin{array}{l}\text { Ingresos superiores } \\
\text { a } 44.769 \text { UVT, e } \\
\text { inferiores o iguales } \\
\text { a } 431.196 \text { UVT } \\
\text { (\$14.777.087.000 por } \\
\text { el año 2019). }\end{array}$ & $\begin{array}{l}\text { Ingresos superiores } \\
\text { a } 431.196 \text { UVT, e } \\
\text { inferiores o iguales } \\
\text { a } 2.160 .692 \text { UVT } \\
\text { (\$74.046.915.000 por el } \\
\text { año 2019). }\end{array}$ \\
\hline
\end{tabular}

Nota: Decreto 957 de 2019. Artículo 2.2.1.13.2.2. *UVT $2019 \$ 34.270$

Fuente: Ministerio de Comercio, Industria y Turismo (2019).

De igual forma, la normatividad expuesta realiza las siguientes consideraciones, para que una empresa sea clasificada como grande sus ingresos por actividades ordinarias anuales tienen que ser mayores a los rangos superiores de las empresas consideradas medianas, por ejemplo, una empresa se ubicará en la clasificación de grande si los ingresos ordinarios anuales que registró fueron más de 2.160.692 UVT.

Cuando la actividad económica que desarrolle la empresa no sea compatible con los sectores señalados en la norma, para efecto de la clasificación se aplicará lo dispuesto en lo relacionado con el sector manufacturero. De la misma forma, cuando la actividad económica de la empresa comprenda más de uno de los sectores indicados y se generen ingresos en cada uno de ellos, la clasificación se hará con base en el sector que represente el mayor ingreso para la empresa. 


\section{Metodología}

El estudio consistió en un análisis descriptivo, analítico de tipo cuantitativo. El procedimiento que se siguió es hipotético-deductivo, el cual inicia con la formulación de la hipótesis, se procedió con la operacionalización de las variables, la recolección y el procesamiento de los datos y la interpretación” (Monje, 2011, p.13).

Se tomó como referencia la información suministrada por la Cámara de Comercio del Sur y Oriente del Tolima, correspondiente a las empresas clasificadas como microempresas registradas al corte del mes de junio de 2020. El total de la base de datos indica que el Espinal cuenta con 1.317 microempresas.

A partir de la organización de la base de datos se identificaron las siguientes variables de análisis: fecha de matrícula mercantil, fecha de renovación de matrícula mercantil, ubicación, clasificación código CIIU, tipo de organización, las cuales permitieron describir y caracterizar la composición del sector micro existente en el municipio del Espinal Tolima al corte del mes de junio de 2020. En los estudios cuantitativos, el análisis de la información recolectada tiene por fin determinar el grado de significación de las relaciones previstas entre las variables.

\section{Resultados y discusión}

Los resultados descritos corresponden al análisis de las variables identificadas en la base de datos que fueron suministradas por la Cámara de Comercio del Sur y Oriente del Tolima (ver figura 2), entregada en el mes de junio de 2020.

Se identifica que, para la fecha de análisis de las 1.317 microempresas matriculadas en la Cámara de Comercio del Sur y Oriente del Tolima, 560 han renovado para el año 2020 su matrícula mercantil y 757 microempresas no han realizado este proceso, se puede considerar que por tema de la actual contingencia de emergencia del Covid-19 que ha afectado las economías de las diferentes empresas disminuyendo sus ingresos, generando la no renovación del registro. Sin embargo, la entidad había ampliado el plazo de registro hasta el 3 de julio de 2020 . 


\section{Figura 2}

Microempresas con renovación de Matrícula Mercantil a Junio de 2020

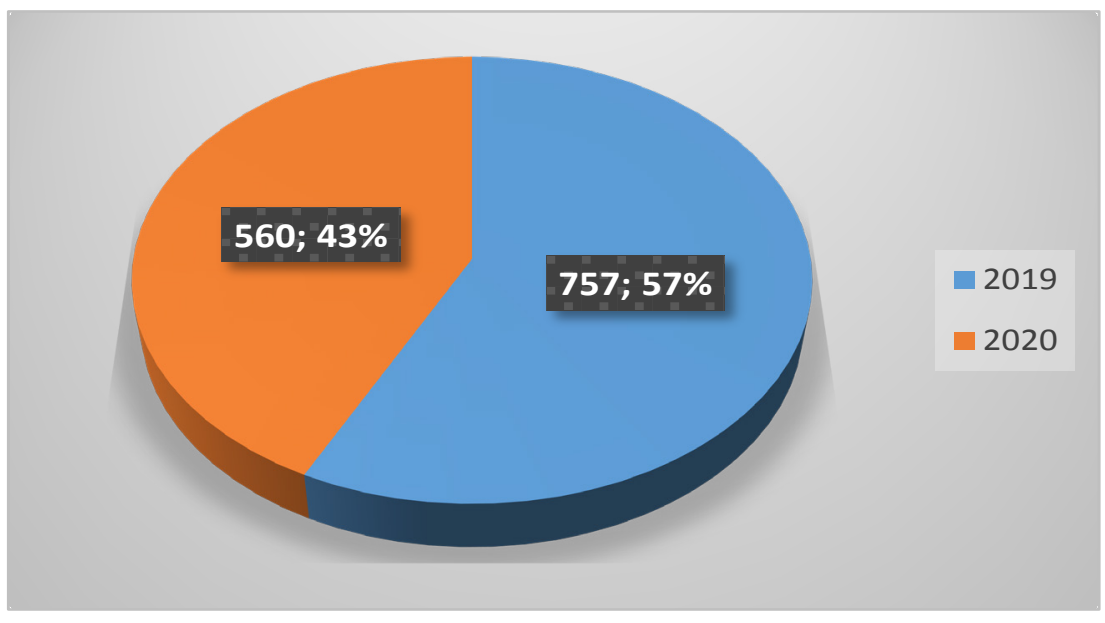

Fuente: elaboración propia (2020).

La organización de las microempresas en el municipio del Espinal Tolima, son de tipo de personas naturales con el $96 \%$ de la población que conforma las microempresas registradas, en segundo lugar, con 49 microempresa que representan el 4\% tiene un tipo de organización de Sociedad Anónima Simple SAS (figura 3).

A partir de la clasificación de las 117 microempresas inscritas a junio de 2020, se identifica el tiempo de la actividad comercial a partir de la fecha de registro de la matrícula en registro mercantil que tienen las microempresas registradas a junio 2020 (ver figura 4). Se identifica que 441 microempresas llevan más de 10 años ejerciendo su actividad comercial, es decir el 33\% de las microempresas, y el 11\% con 150 microempresas tiene menos de un año desde su fecha de registro mercantil como microempresas. 


\section{Figura 3}

Tipo de organización en las Microempresas a junio de 2020

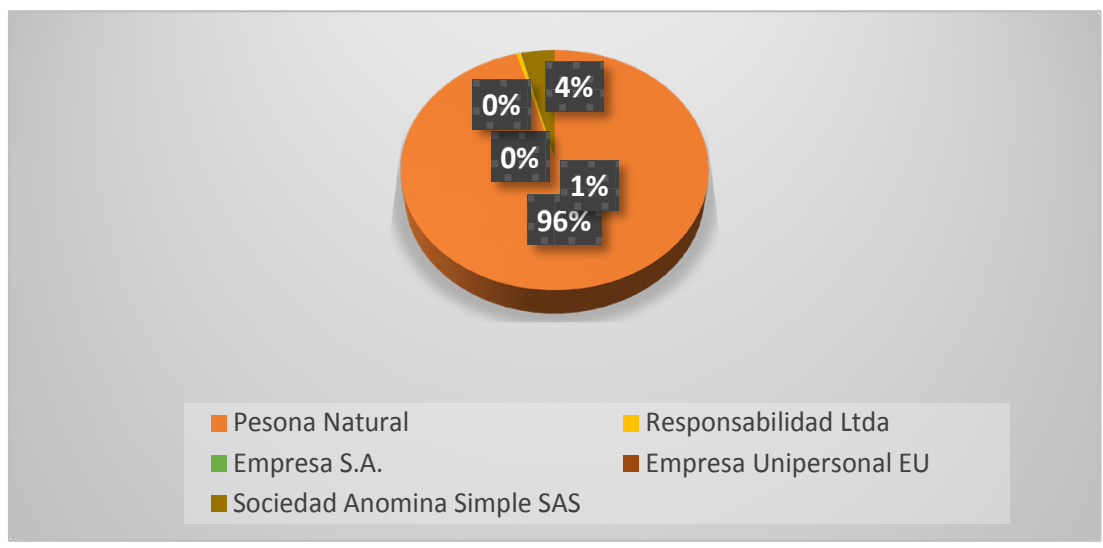

Fuente: elaboración propia (2020).

\section{Figura 4}

Rango de tiempo de Matrícula mercantil para microempresas a junio de 2020

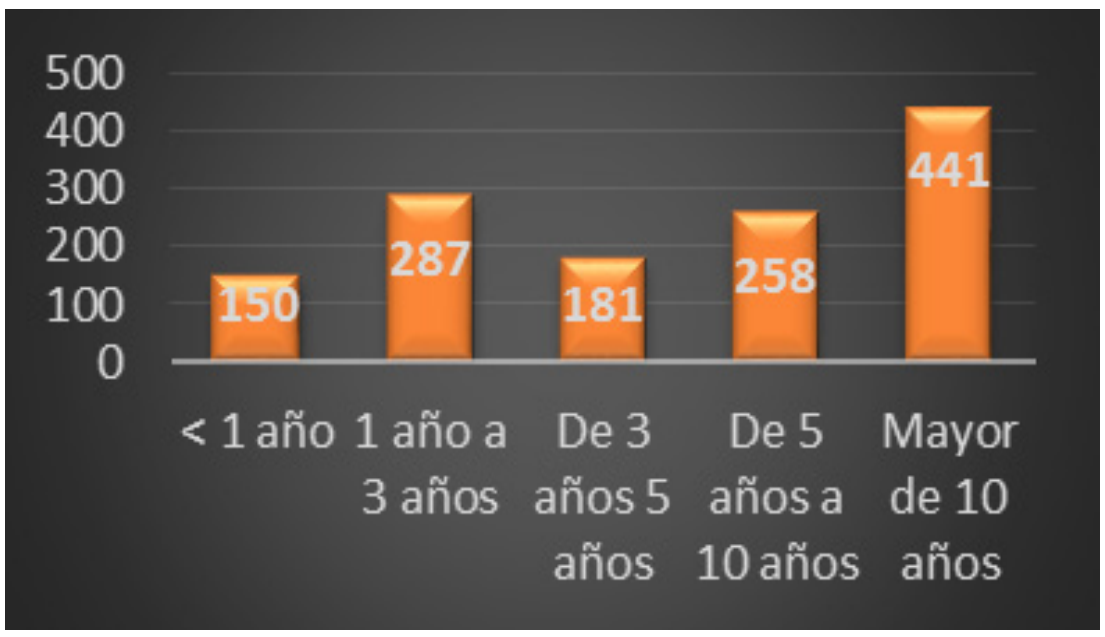

Fuente: elaboración propia (2020). 


\section{Tabla 2}

Clasificación código CIIU para las Microempresas del Espinal a junio de 2020

\begin{tabular}{|c|c|c|c|}
\hline No & Código Actividad CIIU & $\begin{array}{l}\text { No. Micro } \\
\text { Empresas }\end{array}$ & $\%$ \\
\hline 1 & $\begin{array}{l}\text { G4711** "Comercio al por menor en establecimientos no } \\
\text { especializados con surtido compuesto principalmente por } \\
\text { alimentos bebidas o tabaco" }\end{array}$ & 341 & $26 \%$ \\
\hline 2 & $\begin{array}{l}\text { G4719** "Comercio al por menor en establecimientos no } \\
\text { especializados con surtido compuesto principalmente por } \\
\text { productos diferentes de alimentos (víveres en general) bebidas } \\
\text { y tabaco" }\end{array}$ & 103 & $8 \%$ \\
\hline 3 & $\begin{array}{l}\text { G4771 ** "Comercio al por menor de prendas de vestir y } \\
\text { sus accesorios (incluye artículos de piel) en establecimientos } \\
\text { especializados" }\end{array}$ & 96 & $7 \%$ \\
\hline 4 & $\begin{array}{l}\text { G4520 ** Mantenimiento y reparación de vehículos } \\
\text { automotores }\end{array}$ & 70 & $5 \%$ \\
\hline 5 & $\begin{array}{l}\text { G4723** "Comercio al por menor de carnes (incluye aves de } \\
\text { corral) productos cárnicos pescados y productos de mar en } \\
\text { establecimientos especializados" }\end{array}$ & 67 & $5 \%$ \\
\hline 6 & $\begin{array}{l}\text { G4752 ** "Comercio al por menor de artículos de ferretería } \\
\text { pinturas y productos de vidrio en establecimientos } \\
\text { especializados" }\end{array}$ & 66 & $5 \%$ \\
\hline 7 & $\begin{array}{l}\text { G4773** "Comercio al por menor de productos farmacéuticos } \\
\text { y medicinales cosméticos y artículos de tocador en } \\
\text { establecimientos especializados" }\end{array}$ & 63 & $5 \%$ \\
\hline 8 & $\begin{array}{l}\text { G4761 ** "Comercio al por menor de libros periódicos } \\
\text { materiales y artículos de papelería y escritorio en } \\
\text { establecimientos especializados" }\end{array}$ & 51 & $4 \%$ \\
\hline 9 & $\begin{array}{l}\text { G4721 ** "Comercio al por menor de productos agrícolas para } \\
\text { el consumo en establecimientos especializados" }\end{array}$ & 43 & $3 \%$ \\
\hline 10 & $\begin{array}{l}\text { G4759 ** "Comercio al por menor de otros artículos } \\
\text { domésticos en establecimientos especializados" }\end{array}$ & 41 & $3 \%$ \\
\hline 11 & $\begin{array}{l}\text { G4530** "Comercio de partes piezas (autopartes) y accesorios } \\
\text { (lujos) para vehículos automotores" }\end{array}$ & 36 & $3 \%$ \\
\hline 12 & $\begin{array}{l}\text { G4741 ** "Comercio al por menor de computadores } \\
\text { equipos periféricos programas de informática y equipos de } \\
\text { telecomunicaciones en establecimientos especializados" }\end{array}$ & 33 & $3 \%$ \\
\hline
\end{tabular}

Fuente: DIAN (2020). 


\section{Tabla 2}

Clasificación código CIIU para las Microempresas del Espinal a junio de 2020 (Continuación)

\begin{tabular}{clcc} 
Código Actividad CIIU & \multicolumn{1}{c}{$\begin{array}{c}\text { No. Micro } \\
\text { Empresas }\end{array}$} & \% \\
\hline 13 & $\begin{array}{l}\text { G4541 ** "Comercio de motocicletas y de sus partes piezas } \\
\text { y accesorios" }\end{array}$ & 28 & $2 \%$ \\
\hline $14 \quad \begin{array}{l}\text { G4754 ** "Comercio al por menor de electrodomésticos y } \\
\text { gasodomesticos de uso doméstico muebles y equipos de } \\
\text { iluminación" }\end{array}$ & 28 & $2 \%$ \\
\hline 15 & $\begin{array}{l}\text { Otras Actividades CIIU * "corresponde a 35 actividades CIIU” } \\
\text { TOTAL DE MICROEMPRESAS }\end{array}$ & $\mathbf{1 . 3 1 7}$ & $\mathbf{1 0 0 \%}$ \\
\hline
\end{tabular}

Fuente: DIAN (2020).

En la tabla 2. se agrupa el 80/20 de los datos, identificando que la actividad comercio al por menor en establecimientos no especializados con surtido compuesto principalmente por alimentos bebidas o tabaco con código CIIU 4711 y con 341 microempresas son las que más se encuentran matriculadas ejerciendo esta actividad, también se identifica que dentro de este $80 \%$ de microempresas 996 desarrollan actividades de tipo comercial y 70 microempresas prestan servicios, en este caso mantenimiento y reparación de vehículos automotores, del $20 \%$ de la población se puede describir que en promedio corresponde a 7 microempresas que desarrollan otro tipo de actividad clasificadas en el CIIU.

\section{Tabla 3}

Clasificación del número de microempresas de acuerdo a su ubicación

\begin{tabular}{llcc}
\hline No. & & No. Microempresas & $\%$ \\
\hline 1 & CENTRO & 525 & $40 \%$ \\
\hline 2 & CHICORAL & 133 & $10 \%$ \\
\hline 3 & CABALLERO Y GONGORA & 87 & $7 \%$ \\
\hline 4 & SAN RAFAEL & 67 & $5 \%$ \\
\hline 5 & SANTA MARGARITA MARIA & 45 & $3 \%$ \\
\hline 6 & LIBERTADOR & 44 & $3 \%$ \\
\hline
\end{tabular}

Fuente: elaboración propia (2020). 


\section{Tabla 3}

Clasificación del número de microempresas de acuerdo a su ubicación (Continuación)

\begin{tabular}{|c|c|c|c|}
\hline No. & UBICACIÓN & No. Microempresas & $\%$ \\
\hline 7 & RONDON & 43 & $3 \%$ \\
\hline 8 & BALKANES & 32 & $2 \%$ \\
\hline 9 & ISAIAS OLIVAR & 31 & $2 \%$ \\
\hline 10 & LA MAGDALENA & 28 & $2 \%$ \\
\hline 11 & BETANIA CAMPESTRE & 25 & $2 \%$ \\
\hline 12 & LA ESPERANZA & 22 & $2 \%$ \\
\hline 13 & VILLA CATALINA & 21 & $2 \%$ \\
\hline 14 & ZONA RURAL & 21 & $2 \%$ \\
\hline \multirow[t]{2}{*}{15} & OTROS BARRIOS & 193 & $15 \%$ \\
\hline & TOTAL MICROEMPRESAS & 1.317 & $100 \%$ \\
\hline
\end{tabular}

Fuente: elaboración propia (2020).

En la tabla 3, al sectorizar las 1.317 microempresas registradas en el Espinal Tolima a junio de 2020, se identifica que el $85 \%$ se concentran en 14 áreas de municipios, siendo el centro con el $40 \%$ de representación, y un $15 \%$ de la población se concentran en otras 43 zonas.

\section{Discusión}

La caracterización realizada, permite comprender ciertas cualidades específicas que tienen las microempresas del Espinal Tolima, matriculadas en cámara de comercio al cierre del periodo junio de 2020, por lo que Cardozo (2006) señala que la microempresa como ente que participa de la dinámica económica capaz de generar empleos, las cuales permiten evidenciar una realidad como unidad productiva de pequeña escala que a partir de la flexibilidad en sus procesos las hace capaz de ajustarse a condiciones del mercado y mantener su productividad, pero resaltando que la tecnología es la clave para la competitividad. 
Se debe considerar la participación que tienen este tipo de empresas en la economía, ya que se han convertido en factores importantes para el avance económico de las regiones donde existen, debido a que contribuye a disminuir los niveles de desempleo (Cardozo, 2006) de la misma forma, que su “desarrollo empresarial está asociado a la forma como se aborden los procesos que emprenden en sus actividades, lo que se traducirá en mayores o menores niveles de competitividad" (García et al., 2019, p. 34). Esta caracterización de microempresas permite identificar que estas nacen por la necesidad de los individuos de encontrar una fuente de empleo, también de la iniciativa de algunas personas que poseen una serie de aptitudes y habilidades para llevar a cabo una actividad. (Duran et al., 2004).

\section{Conclusiones}

Frente al tejido empresarial las micro del Espinal se puede concluir que, estas empresas tienen la mayor participación en el tipo de empresas que dinamizan la economía, por tanto, se percibe la importancia e impacto que generan en el desarrollo económico de la región y a nivel general en la economía del país. Por lo tanto, se considera que estas tienen ventajas frente a las grandes empresas, se puede señalar, por ejemplo, la posibilidad y facilidad de adaptación a condiciones de entornos cambiantes.

En el Espinal se identifican que este tejido empresarial al cierre de junio de 2020 lo conforman 1.317 microempresas, 560 con renovación en cámara de comercio al cierre del análisis y 757 que se registran sin la renovación. De igual forma, se puede concluir que la figura de persona natural son las que representan este grupo de empresas con una representación del 96\% del total de las microempresas existentes. Por último, este tipo de análisis permite identificar características y variables que describen este grupo de empresas de gran importancia y aporte a la economía de la región.

\section{Referencias bibliográficas}

Batista, A., y Guacari, W. (2018) Gestión empresarial y competitividad en las mipymes del centro comercial nueva Colombia de la ciudad de Cartagena. Revista INNOVA ITFIP, 3 (1), 75-81. https://revistainnovaitfip.com/index.php/ innovajournal/article/view/41/56 
Bautista, M., Hernández, C., y Mendoza, M. (2020). Responsabilidad social empresarial en El parque ecoturístico "Bosque de las Truchas", en Huasca de Ocampo, Hidalgo, Mexico. En: Chirinos, Y., Ramírez, A., Godínez, R. Barbera, N. y Rojas, D. (2020). (Eds.). Tendencias en la Investigación Universitaria. Una visión desde Latinoamérica. Vol. XII, 61 - 59. Coro. Venezuela. Fondo Editorial Servando Garcés. www.doi.org/10.47212/tendencias2020vol.xii.4

Barragán, F., y Quintero, I. V. (2019). Percepción de los pequeños comerciantes de honda con relación al tema de cultura organizacional, contable e innovación. Revista Innova ITFIP, 4(1), 33-43. Recuperado a partir de http://revistainnovaitfip.com/index.php/innovajournal/article/view/45

Barragán, F., y Zarete, S. I. (2017). Modelo resignifiación para incentivar el uso de las tic en la práctica pedagógica en coreducación. Revista Innova ITFIP, 1(1), 36-46. Recuperado a partir de http://revistainnovaitfip.com/index.php/ innovajournal/article/view/11

Benito, H.S. (2007). El papel de las microempresas en el desarrollo económico regional: las redes de cooperación empresarial en España. Universidad Europea de Madrid. Facultad de Economía, Derecho y Empresariales. Dpto. Economía de la Empresa. Recuperado de: https://webs.ucm.es/info/revesco/ txt/REVESCO\%20N\%2099.2\%20Sonia\%20BENITO\%20HERNANDEZ. htm\#_ftn1

Cardozo, E. (2006). La conceptualización de microempresa, microemprendimientos y unidad productiva de pequeña escala. Copérnico Revista Arbitrada Interdisciplinaria.

Cámara de Comercio del Sur y Oriente de Tolima. Renovación registro mercantil 2020. Recuperado de: http://www.ccsurortolima.org.co/

Ceballos, O. I., Mejía, L. A., y Arango, D. (2019). Auditoria de usabilidad de herramientas implementadas en plataformas virtuales para ofertar servicios con responsabilidad social. Revista Innova ITFIP, 5(1), 64-77. 
Recuperado a partir de DIAN" http://www.revistainnovaitfip.com/index. php/innovajournal/article/view/56

DIAN (2020). Formularios instructivos Recuperado de: www.dian.gov.co/ atencionciudadano/formulariosinstructivos/Formularios/2020/ Formulario_2593_2020.pdf

Díaz, S. (2010). La microempresa en el desarrollo perspectivas. núm. 25, enero-junio, 2010, pp. 271-282 Universidad Católica Boliviana San Pablo Cochabamba, Bolivia. Recuperado de: https://www.redalyc.org/pdf/4259/425942454014. pdf

Díaz, M., Palma, E., Leiva, F., Varón O., Alarcón, A...Sandoval, L. (2018) Avances de investigación en ciencias económicas, administrativas y contables Editorial: Instituto Tolimense de Formación Técnica Profesional-ITFIP 176 p. ISBN: 978-958-59986-4-3

Domínguez, J. (2016). Mipymes generan alrededor del 67\% del empleo en Colombia. Revista Dinero. Recuperado de https://www.dinero.com/edicion-impresa/ pymes/articulo/evolucion-y-situacion-actual-de-las-mipymes-encolombia/222395

Decreto 957 de Junio 5 de 2019. Ministerio de industria y Comercio. Diario oficial de la Republica de Colombia. 5 de junio de 2019. Recuperado de https://diariooficial.vlex.com.co/vid/decreto-numero-957-2019-791512045

Duran, E., Montes, P. S., Padilla, L. D. (2004). Caracterización de la microempresa En el sector urbano del municipio de Sincelejo. https://repositorio.unisucre.edu. co/bitstream/001/812/1/T338.642\%20D948.pdf

García, S., Prieto, R., Roja, A., Romero, W. (2019). Caracterización de las microempresas. Una aproximación desde las ciudades de Cali y Palmira en Colombia. DOI: 10.17081/bonga/2824.c1. https://www.researchgate. 
net/publication/331608625_Caracterizacion_de_las_microempresas_Una_ aproximacion_desde_las_ciudades_de_Cali_y_Palmira_en_Colombia/ citations

Guerrero, M. (2001, Julio 11). Papel de las microempresas para el desarrollo económico. Recuperado de https://www.gestiopolis.com/papel-microempresasdesarrollo-economico/

Martínez, N. R. (1989). Racionalidad, Riesgo y Viabilidad de la Microempresa. Microempresas y Economía Popular. Fundación Grupo Esquel. Guatemala. Recuperado de: https://repositorio.cepal.org/bitstream/handle/11362/29712/ S338642C678_es.pdf? sequence $=1 \&$ isAllowed $=y$

Ministerio de Comercio, Industria y Turismo. (2019). Decreto 957 de 2019. Recuperado de: www.mincit.gov.co/prensa/noticias/industria/gobierno-expide-nuevaclasificacion-de-empresas-a

Monje, A.C. (2011). Metodología de la Investigación Cuantitativa y Cualitativa. Guía Didáctica. Universidad Surcolombia. Neiva Colombia. Recuperado de: https:/www.uv.mx/rmipe/files/2017/02/Guia-didactica-metodologia-de-lainvestigacion.pdf

Moreno, O. y Valencia, Q. (2019). Las organizaciones y el impacto de las tecnologías emergentes. En: La industria 4.0, desde la perspectiva organizacional. Yandar, L. y Moreno, O. compiladores. Santa Ana de Coro (Venezuela). Fondo Editorial Universitario Servando Garcés de la Universidad Politécnica Territorial de Falcón Alonso Gamero (UPTAG), (Colección Unión Global). 13 - 32. www.doi.org/10.47212/industria4.0-2

Instituto Tolimense de Formación Técnica Profesional - ITFIP.

Palma, E., Escovar, E., Bedoya, D., Garrazza, N., Fenoglio, N., Berizzo, L., Volker, R., Salgado, L., García, J. \& Moreno, L. (2019). La Gestión Investigativa en las Mipymes, una mirada desde Colombia, México y Argentina. Edición 
1. Espinal Tolima. Instituto Tolimense de Formación Técnica ProfesionalITFIP

Red de Cámaras de Comercio. Confecamaras. (2020). Encuesta Nacional de Medición de Impacto del COVID-19 para el sector empresarial. Recuperado de: http://www.confecamaras.org.co/analisis-economico

Restrepo, J.M. (2019). Gobierno expide nueva clasificación de empresas a partir de sus ingresos. Ministerio de Comercio, Industria y Turismo. Recuperado de: https://www.mincit.gov.co/prensa/noticias/industria/gobierno-expidenueva-clasificacion-de-empresas-a

Reyes, G. E., Hernández, O. G., \& González, F. (2019). Liderazgo comunitario y su influencia en la sociedad como mejora del entorno rural. Revista Innova ITFIP, 5(1), 15-27. Recuperado a partir de http://www.revistainnovaitfip. com/index.php/innovajournal/article/view/52

Varón, O., Gutiérrez, D. y Rodríguez, W. (2018). Procesos contables aplicados por los comerciantes al por menor del municipio de Icononzo -Tolima para identificar necesidades de capacitación en el área. Revista INNOVA ITFIP, 3 (1), 27-34. Recuperado de: http://www.revistainnovaitfip.com/index.php/ innovajournal/article/view/36/48 